\title{
Synchronous endometrial and ovarian cancer: a rare presentation
}

\author{
Reena Yadav, Nishtha Jaiswal*, Ruby Yadav, Manisha Kumar
}

Department of Obstetrics and Gynecology, Lady Hardinge Medical College, New Delhi, India

Received: 06 July 2020

Accepted: 05 August 2020

\section{*Correspondence:}

Dr. Nishtha Jaiswal,

E-mail: nishtha.amu@gmail.com

Copyright: (C) the author(s), publisher and licensee Medip Academy. This is an open-access article distributed under the terms of the Creative Commons Attribution Non-Commercial License, which permits unrestricted non-commercial use, distribution, and reproduction in any medium, provided the original work is properly cited.

\begin{abstract}
Synchronous primary cancers are relatively uncommon in the general population. About $0.5-1.7 \%$ of gynecological malignancies have synchronous primary cancer of female genital tract. Amongst the synchronous gynecological malignancies synchronous endometrioid carcinoma is most common and has good prognosis. Patients with synchronous endometrioid tumors of endometrium and ovary are usually younger, have low grade number, and their prognosis is better than other histologic types. The authors are presenting a case of 38 years old nulliparous obese woman with pain in abdomen and heavy menstrual bleeding for a duration of four months. The MRI pelvis was suggestive of well defined, lobulated, complex, solid cystic multiseptated lesion measuring $8.8 \times 7.7 \times 8.8 \mathrm{~cm}$ in right adnexa, with anteverted uterus, and a bulky indistinct emdomyometrial junction. Histopathology revealed synchronous endometrial carcinoma of both uterus and ovary.
\end{abstract}

Keywords: Endometrial cancer, Ovarian cancer, Synchronous tumors

\section{INTRODUCTION}

Synchronous primary tumor account for $0.5-1.7 \%$ of all gynecological malignancies. ${ }^{1}$ The most common $40 \%$ $53 \%$ synchronous primary tumors of genital tract are ovarian and endometrial cancers. ${ }^{2}$

Patients with synchronous endometrioid tumors of endometrium and ovary are generally younger, have low grade malignancy, and prognosis is better than other histologic types. ${ }^{3-5}$

It is challenging diagnostically and therapeutically when there is similar histology.

\section{CASE REPORT}

A 38-year-old nulliparous woman presented with chief complain of irregular and prolonged bleeding of four months duration. She was obese with BMI $40 \mathrm{~kg} / \mathrm{m}^{2}$. She was detected with hypothyroidism twenty years back, was hypertensive since 4 years and was recently diagnosed with diabetes mellitus. There was no history of white discharge per vaginum, hormonal pill intake, weight loss and bladder or bowel complaints. On abdominal examination a mass corresponding to 16-week size of uterus was felt. Vaginal examination suggested the mass was in the right adnexa with bulky uterus. The MRI report showed a well-defined, lobulated complex, solid cystic multiseptated mass measuring $8.8 \times 7.7 \times 8.8$ $\mathrm{cm}$ in the right adnexa, and the uterus was bulky with indistinct endo-myometrial junction, with the left ovary visualized and normal. Endometrial biopsy was taken and histopathological examination was reported as endometrial adenocarcinoma. Amongst tumor markers CA 125 was 212.7U/1. Considering both ovarian and uterine malignancy with an unclear primary tumor, an exploratory laparotomy with peritoneal cytology, total abdominal hysterectomy, bilateral salpingooopherectomy, infracolic omentectomy and pelvic lymphadenectomy was performed. Intraoperatively the uterus was 6 to 8 weeks size and there was a $10 \times 10 \mathrm{~cm}$ solid cystic mass arising from right ovary. The ascitic fluid cytology was negative for malignant cells. 
Intraoperative frozen section analysis of the pelvic lymph nodes showed no evidence of pelvic lymph node metastasis. The intraoperative and postoperative course of the patient was uncomplicated. The final histological report confirmed a moderately differentiated endometrioid adenocarcinoma of the endometrium (pathologic stage classification (pTNM) pT1bN0Mx without lymphovascular space invasion). In addition, a synchronous right ovarian moderately differentiated endometrioid carcinoma (pT1c2NOMx) was found.

The final histopathological examination revealed diagnosis of synchronous independent primary malignancies arising from the endometrium and ovary. The patient received adjuvant chemoradiation and is currently on follow-up.

\section{DISCUSSION}

Ulbright and Roth proposed the pathological criteria for synchronous gynecological tumors. ${ }^{6}$ They suggested either the tumors must have different histopathological origin, or they should fulfill all the minor criteria (tumors must be restricted, no distant metastasis, no connection between the tumors, no lymphovascular tumor emboli). In this case the patient presented with abnormal uterine bleeding, was diagnosed as synchronous endometrial and ovarian cancer (SEOC) of endometrioid histology with uterine corpus tumor PT1b N0 Mx and ovarian malignancy PT1c2 N0 Mx. Primary and metastatic tumors can also be differentiated using immunohistochemistry and DNA flow cytometry. The differentiation between the two is important to determine optimal adjuvant treatment. Mostly the diagnosis is made only after surgery with final histopathology report. As tumors are diagnosed in early stage, follow-up is required in most of the cases for the need of adjuvant chemotherapy or radiotherapy, whereas metastatic tumors always need chemoradiation.

The average age of diagnosis of the endometrial carcinoma is 60 years. Women diagnosed at younger than 40 years make up only 5\%. Morbid obesity, chronic anovulation and hereditary syndromes are high risk factors for endometrial carcinoma. Poor prognostic factors for dissemination of disease include high tumor grade, advanced surgical stage, and lymphovascular space invasion.

Ovarian endometrioid carcinoma account for only $10 \%$ of ovarian carcinomas. Primary ovarian cancer express PAX-8 which is not expressed in endometrial primaries, whereas endometrioid adenocarcinoma of endometrium characteristically express ER, PR, KRAS, PTEN and $\beta$ catenin. ${ }^{7,8}$ Adequate surgical staging is the mainstay in the management of SEOC. Accurate diagnosis of SEOC is important, because it is most commonly diagnosed in FIGO stage IA and would be adequately treated by surgery alone followed by regular follow-up, whereas primary endometrial or ovarian cancer with metastasis to each other necessitates aggressive adjuvant chemotherapy or radiotherapy. Adjuvant treatment has not shown any significant advantage in this group of patients when compared to regular follow up after adequate surgical staging. ${ }^{9}$ In the present case, following surgery adjuvant treatment was given and patient has completed 10 months of disease-free survival and presently under regular follow up. The 5-year overall survival of women with SEOC found to be better $(92.8 \%)$ than that of women with either primary ovarian or endometrial cancer $(48.5 \%) .^{10}$

Symptoms characteristic of endometrial cancer are mostly present in patients with SEOC. The most frequently reported symptoms are abnormal vaginal bleeding (42-70\%), pain in lower abdomen (17-44\%), palpable lump in pelvis $(28-40 \%)$, and they have an elevated concentration of CA125(65\%). ${ }^{11}$

Following literature review, apart from synchronous presentation of the carcinoma of ovary and endometrium, few cases of carcinoma of the ovary and cervix, endometrium and cervix, and ovary and fallopian tube are also reported. The maximum number of affected organs in synchronous gynecological malignancy reported is five (ovary, bilateral fallopian tubes, endometrium and cervix).

\section{CONCLUSION}

Young women with endometrial cancer are at increased risk of SEOC. Therefore, careful histological assessment of uterus and both ovaries should be done. Differentiation is important as it affects tumor staging and prognosis. Multidisciplinary team and patient oriented approach are key to successful management and increase in life expectancy of patient with synchronous primary malignant tumors.

\section{Funding: No funding sources \\ Conflict of interest: None declared \\ Ethical approval: Not required}

\section{REFERENCES}

1. Tong SY, Lee YS, Park JS, Bae SN, Lee JM, Namkoong SE. Clinical analysis of synchronous primary neoplasms of the female reproductive tract. Eur J Obstet Gynecol Reprod Biol. 2008;136:78-82.

2. Gungor T, Kanat Pektas M, Ustunyurt E, Mollamahmutoglu L. Synchronous primary tumors of the female genital tract: a single center experience. Arch Gynecol Obstet. 2009;279:667-72.

3. Rodriguez AM, Schmeler KM, Kuo YF. Disparities in endometrial cancer outcomes between nonhispanic white and hispanic women. Gynecol Oncol. 2014;135(3):525-33.

4. Manchana T, Sirisabya N. Clinicopathologic variables and survival comparison of patients with synchronous endometrial and ovarian cancers versus 
primary endometrial cancer with ovarian metastasis. Asian Pac J Cancer Prev. 2008;9(3):403-7.

5. Chiang YC, Chen CA, Huang CY, Hsieh CY, Cheng WF. Synchronous primary cancers of the endometrium and ovary. Int $\mathbf{J}$ Gynecol Cancer. 2008;18:159-64.

6. Ulbright TM, Roth LM. Metastatic and independent cancers of the endometrium and ovary: a clinicopathologic study of 34 cases. Hum Pathol. 1985;16:28-34.

7. Goyal A, Masand RP, Roma AA. Value of PAX-8 and SF-1 immunohistochemistry in the distinction between female adnexal tumor of probable wolffian origin and its mimics. Int $\mathbf{J}$ Gynecol Pathol. 2016;35:167-75.

8. Lax SF. Pathology of endometrial carcinoma. Adv Exp Med Biol. 2017;943:75-96.

9. Chiang YC, Chen CA, Huang CY, Hsieh CY, Cheng WF. Synchronous primary cancers of the endometrium and ovary. Int $\mathrm{J}$ Gynecol Cancer. 2008;18:159-64.

10. Soliman PT, Solmovitz BM, Broaddus RR, Sun CC, Oh JC, Eifel PJ, et al. Synchronous primary cancers of endometrium and ovary: a single institution review of 84 cases. Gynecol Oncol. 2004;94:456-62.

11. Lim YK, Padma R, Foo L, Chia YN, Yam P, Chai J, et al. Survival outcome of women with synchronous endometrium and ovary cancers: A 10 years retrospective cohort study. J Gynecol Oncol. 2011;22:239-43.

Cite this article as: Yadav R, Jaiswal N, Yadav R, Kumar M. Synchronous endometrial and ovarian cancer: a rare presentation. Int J Reprod Contracept Obstet Gynecol 2020;9:3889-91. 